CLINICAL STUDY

\title{
Inflammatory mediators in morbidly obese subjects: associations with glucose abnormalities and changes after oral glucose
}

\author{
Dag Hofs $ø^{1}$, Thor Ueland ${ }^{2}$, Helle Hager ${ }^{3}$, Trond Jenssen ${ }^{4,5}$, Jens Bollerslev ${ }^{4,6}$, Kristin Godang ${ }^{2}$, Pål Aukrust ${ }^{2}$, \\ Jo Røislien ${ }^{1,7}$ and Jøran Hjelmesæth ${ }^{1}$ \\ ${ }^{1}$ Morbid Obesity Center, Vestfold Hospital Trust, PO Box 2168, 3103 Tonsberg, Norway, ${ }^{2}$ Research Institute of Internal Medicine, Rikshospitalet \\ University Hospital, Oslo, Norway, ${ }^{3}$ Department of Clinical Chemistry, Vestfold Hospital Trust, Tonsberg, Norway, ${ }^{4}$ Department of Medicine, \\ Rikshospitalet University Hospital, Oslo, Norway, ${ }^{5}$ Institute of Clinical Medicine, University of Tromsø, Tromsø, Norway, ${ }^{6}$ Faculty Division \\ Rikshospitalet, University of Oslo, Oslo, Norway and ${ }^{7}$ Department of Biostatistics, Institute of Basic Medical Sciences, University of Oslo, Oslo, Norway
}

(Correspondence should be addressed to D Hofso; Email: dag.hofso@siv.no)

\begin{abstract}
Objective: To explore inflammatory mediators in morbidly obese (MO) subjects with various categories of glucose tolerance and to study the changes in these mediators after an oral glucose load.

Design: Cross-sectional and experimental study.

Methods: A total of $144 \mathrm{MO}$ subjects were classified into three categories: normal glucose tolerance (NGT); pre-diabetes; and new onset diabetes mellitus (NODM) were included, as were 27 normal weight normoglycemic controls. Serum osteoprotegerin (OPG), visfatin, leptin, adiponectin, interleukin-1 receptor antagonist (IL-1Ra), and C-reactive protein (CRP) were analyzed during an oral glucose tolerance test (OGTT).

Results: Fasting levels of leptin and IL-1Ra were consistently higher in obese persons $(P<0.001$ and $P<0.05)$. MO subjects with NGT had higher CRP levels $(P<0.001)$ and lower adiponectin levels $(P<0.05)$ compared to controls. Yet when compared with MO subjects with NODM, those with NGT had lower CRP levels and higher adiponectin levels (both $P<0.05$ ). Baseline OPG and visfatin levels did not differ between the groups $(P=0.326$ and $P=0.198)$. During OGTT, OPG levels decreased $(P<0.001)$ and visfatin levels increased transiently $(P=0.018)$. The response in OPG and visfatin did not differ between the groups $(P=0.690$ and $P=0.170)$. There were minor changes in adiponectin and leptin levels.

Conclusions: Morbid obesity and glucose intolerance were associated with lower adiponectin levels and higher CRP levels, thus supporting a relationship between obesity, glucose homeostasis, and inflammation. Oral glucose suppressed OPG levels and transiently enhanced visfatin levels independent of obesity and glucose tolerance status, indicating that glucose may be involved in the acute regulation of these proteins.
\end{abstract}

European Journal of Endocrinology $161451-458$

\section{Introduction}

The prevalence of both overweight and obesity is increasing worldwide, and subsequently, so too is the prevalence of type 2 diabetes (1). Obesity and type 2 diabetes are frequently associated with low-grade inflammation (2). Increased plasma concentrations of C-reactive protein (CRP) and interleukin-1 receptor antagonist (IL-1Ra) have been linked to insulin resistance and obesity (3-7). More recently, elevated levels of osteoprotegerin (OPG), a member of the tumor necrosis factor (TNF) receptor superfamily, have been associated with type 2 diabetes $(8,9)$. OPG is mainly produced by osteoblasts, but other cells, including dendritic, smooth muscle, and endothelial cells, also express OPG (10). Moreover, OPG is known to block the effects of the receptor activator of nuclear factor $\kappa \mathrm{B}$ ligand (RANKL) in osteoclasts, various immune cells and endothelial cells, thereby affecting bone metabolism, immunity, and vasculature $(10,11)$. However, the physiological and pathophysiological role of OPG is far from clear.

Rather than being a passive energy store, adipose tissue is now recognized as an important secretory organ producing a range of bioactive proteins called adipokines, which could be involved in the pathogenesis of metabolic complications related to obesity. For instance, leptin is highly correlated with body mass index (BMI) and insulin levels (12). However, the possible associations between visfatin, a recently identified adipokine produced by both visceral and subcutaneous white adipose tissue (13), obesity, and 
type 2 diabetes have been disputed (14-17). Recently, visfatin was found to be essential for the functioning of $\beta$-cells, showing a novel process by which fat cells may modulate insulin secretion (13). Additionally, visfatin displays inflammatory properties (18). In contrast to other adipokines, the levels of the anti-inflammatory adipokine adiponectin are reduced in obesity and type 2 diabetes (19-22). This may further exacerbate the state of low-grade systemic inflammation associated with obesity.

Although a number of studies have examined the regulation of cytokines and adipokines in obesity, the possible role of these pro- and anti-inflammatory substances in relation to impaired glucose tolerance and type 2 diabetes within morbidly obese (MO) persons $\left(\mathrm{BMI} \geq 40\right.$ or $\geq 35 \mathrm{~kg} / \mathrm{m}^{2}$ with a weight-related comorbidity) is far from clear. In order to explore the association between obesity, glucose metabolism, and inflammation, we measured serum levels of OPG, visfatin, leptin, adiponectin, IL-1Ra, and CRP at a fasting state and during an oral glucose tolerance test (OGTT) in both normal weight (NW) normoglycemic subjects and MO subjects with or without abnormal glucose metabolism.

\section{Subjects and methods}

\section{The morbid obesity treatment, bariatric surgery, versus intensive lifestyle intervention study}

Between December 2005 and May 2006, 228 MO patients were consecutively screened at a regional tertiary care center in order to participate in the morbid obesity treatment, bariatric surgery, versus intensive lifestyle intervention (MOBIL) study (ClinicalTrials.gov number NCT00273104). A total of 181 patients were found to be eligible for either bariatric surgery or intensive lifestyle intervention, and were subsequently included in the study. The primary aim of this ongoing study is to compare the effects of both bariatric surgery and intensive lifestyle intervention on various comorbidities, eating behavior, and quality of life. The current substudy had one cross-sectional part (baseline analysis) and one experimental part (OGTT).

\section{Subjects}

At the time of the OGTT, subjects from the MOBIL study who were not MO (BMI $\left.<35 \mathrm{~kg} / \mathrm{m}^{2} ; n=3\right)$, had undergone malabsorptive surgery $(n=3)$, used metformin $(n=3)$, or had known diabetes $(n=28)$ were excluded. Consequently, 144 MO subjects were included in the analysis. Additionally, a control group of 27 persons with NW $\left(18 \mathrm{~kg} / \mathrm{m}^{2}<\mathrm{BMI}<25 \mathrm{~kg} / \mathrm{m}^{2}\right)$ and normal glucose tolerance (NGT) were recruited from healthy employees at Vestfold Hospital Trust.
MO subjects were classified into three categories of glucose tolerance according to the American Diabetes Association criteria (23): NGT (fasting serum glucose $<5.6 \mathrm{mmol} / \mathrm{l}$ and $2-\mathrm{h}$ serum glucose $<7.8 \mathrm{mmol} / \mathrm{l}$ ); pre-diabetes (fasting serum glucose between 5.6 and $6.9 \mathrm{mmol} / \mathrm{l}$ and/or 2-h serum glucose between 7.8 and $11.0 \mathrm{mmol} / \mathrm{l}$ ); and new onset diabetes mellitus (NODM; fasting serum glucose $\geq 7.0 \mathrm{mmol} / \mathrm{l}$ or $2 \mathrm{~h}$ serum glucose $\geq 11.1 \mathrm{mmol} / \mathrm{l})$.

\section{Clinical characteristics}

All participants underwent a medical examination by a physician and demographic data and medical history were recorded on standardized forms. Patients, wearing light clothing and without shoes, were weighed and measured for height. The BMI of each patient was calculated as weight in kilograms divided by the square of the height in meters. Blood pressure was measured with an appropriately sized cuff after at least $5 \mathrm{~min}$ rest with the patient seated in an upright position. Three measurements were made and the average of the second and third measurement was registered and used in the analyses.

\section{Insulin sensitivity and $\beta$-cell function}

Using data from the OGTT, insulin sensitivity was estimated using the insulin sensitivity index $\operatorname{ISI}_{0,120}$ and $\beta$-cell function calculated using the insulinogenic index $\left(\Delta\right.$ insulin $_{30} / \Delta$ glucose $\left._{30}\right)$. ISI I, $120_{\text {correlates well }}$ with the euglycemic clamp (24), whereas $\Delta$ insulin $_{30} /$ $\Delta$ glucose $_{30}$ is widely used as an index of early insulin response (25). The latter also correlates well with the acute insulin response from the i.v. glucose tolerance test (26).

\section{Laboratory analyses}

Blood was collected by venipuncture following an overnight fast. The $75 \mathrm{~g}$ OGTT was performed at $0800 \mathrm{~h}$ and blood samples were drawn both before glucose ingestion and 30 and 120 min after. Serum samples from the OGTT were separated after $30 \mathrm{~min}$ and either stored at $-80{ }^{\circ} \mathrm{C}$ or analyzed the same day. Analyses of serum glucose and blood lipids were performed using dry reagent slide technology on the Vitros 950 Analyzer (Ortho-Clinical Diagnostics, New York, NY, USA). $\mathrm{HbA}_{1} \mathrm{c}$ was analyzed using high performance liquid chromatography on Tosoh HLC723 G7 (Tosoh Corporation, Tokyo, Japan). Serum levels of insulin were measured by radio immunoassay (Insulin Coat-A-Count, DPC, Los Angeles, CA, USA), while serum levels of visfatin (Phoenix Europe $\mathrm{GmbH}$, Karlsruhe, Germany), IL-1Ra (Biosource, Invitrogen Corporation), CRP (27), OPG (R\&D systems, Minneapolis, MN, USA), adiponectin (R\&D systems), 
and leptin (R\&D systems) were measured using enzyme immunoassays on stored samples. All samples were measured in duplicate and serial samples from a given individual were run at the same time. Intra- and inter-assay coefficient of variation were $<10 \%$ for all assays.

\section{Statistical analysis}

Data are presented as either mean (s.D.) or number (\%) unless otherwise specified. Skewed data (insulin, triglycerides, high-density lipoprotein (HDL) cholesterol, OPG, visfatin, adiponectin, IL-1Ra, and CRP) were transformed using natural logarithms in order to compare means and meet the assumptions of the correlation and regression analyses. Two subjects with extremely high visfatin levels $(>700 \mathrm{ng} / \mathrm{ml})$ were excluded from the analysis. To compare differences between groups at baseline, independent sample $t$-test or one-way ANOVA with post-hoc comparisons were used for continuous data, while $\chi^{2}$ was used for categorical data. We used two-way repeated measures ANOVA, with time and group as independent variables, to evaluate changes on variables measured during OGTT (effect of time) and to examine differences in changes in these variables between groups (interaction between time and group; effect of time $\times$ group). When a statistically significant main effect of time was found, post-hoc comparisons were performed. Least significant difference procedure was used for the adjustment of multiple comparisons. Pearson's correlation was calculated to explore the associations between continuous variables. Stepwise multiple regression analysis was used to identify independent determinants for insulin sensitivity $\left(\mathrm{ISI}_{0,120}\right)$. $P$ values $<0.05$ were considered statistically significant.

\section{Approvals and ethics}

The Regional Ethics Committees for Medical Research approved the study protocol and the study was performed in accordance with the Declaration of Helsinki. All participants gave informed written consent before enrollment. We certify that all applicable institutional and governmental regulations concerning the ethical use of human volunteers were followed during this research.

\section{Results}

\section{Clinical and biochemical characteristics}

All but four of the participants were of Europoid origin. Their mean age was 43 (11) years, while 121 of the subjects $(71 \%)$ were women. Clinical and biochemical characteristics according to obesity and glucose tolerance categories are shown in Table 1.

\section{Baseline concentrations of cytokines and adipokines}

Baseline OPG and visfatin levels did not differ significantly between groups (Fig. 1A and B). The serum levels of leptin and IL-1Ra were significantly higher in MO subjects when compared to those of the NW normoglycemic control group (Fig. 1C and D).

Table 1 Clinical and biochemical characteristics of normal weight and morbidly obese subjects.

\begin{tabular}{|c|c|c|c|c|c|c|c|}
\hline & \multirow{2}{*}{$\begin{array}{l}\text { Normal } \\
\text { weight } \\
\text { NGT } \\
(n=27)\end{array}$} & \multicolumn{3}{|c|}{ Morbidly obese } & \multicolumn{3}{|c|}{$P$ values } \\
\hline & & $\begin{array}{l}\text { NGT } \\
(n=57)\end{array}$ & $\begin{array}{l}\text { Pre-DM } \\
(n=66)\end{array}$ & $\begin{array}{l}\text { NODM } \\
(n=21)\end{array}$ & $\begin{array}{c}\text { NW NGT } \\
\text { versus } \\
\text { MO NGT }\end{array}$ & $\begin{array}{l}\text { MO NGT } \\
\text { versus } \\
\text { Pre-DM }\end{array}$ & $\begin{array}{c}\text { MO NGT } \\
\text { versus } \\
\text { NODM }\end{array}$ \\
\hline Female (yes) & $18(67 \%)$ & $44(77 \%)$ & $44(67 \%)$ & $15(71 \%)$ & 0.305 & 0.197 & 0.599 \\
\hline Age (year) & $42(9)$ & $40(11)$ & $43(10)$ & $48(11)$ & 0.402 & 0.058 & 0.004 \\
\hline $\mathrm{BMI}\left(\mathrm{kg} / \mathrm{m}^{2}\right)$ & $22.6(1.5)$ & $44.0(5.6)$ & $46.7(6.7)$ & $46.1(4.8)$ & $<0.001$ & 0.008 & 0.132 \\
\hline $\mathrm{HbA}_{1} \mathrm{c}(\%)$ & $5.2(0.3)$ & $5.2(0.3)$ & $5.6(0.4)$ & $6.1(0.7)$ & 0.379 & $<0.001$ & $<0.001$ \\
\hline Glucose, fasting (mmol/l) & $4.8(0.3)$ & $5.1(0.3)$ & $6.1(0.4)$ & $8.2(1.8)$ & 0.062 & $<0.001$ & $<0.001$ \\
\hline Insulin, fasting (pmol/l) & $72(19)$ & $156(60)$ & $207(93)$ & $244(110)$ & $<0.001$ & $<0.001$ & $<0.001$ \\
\hline $\mathrm{ISI}_{0,120}\left(\mathrm{mg} \mathrm{l}^{2} / \mathrm{mmol} \mathrm{mU} \min \right)$ & $43(8)$ & $33(10)$ & $23(7)$ & $12(7)$ & $<0.001$ & $<0.001$ & $<0.001$ \\
\hline$\Delta \mathrm{Ins}_{30} / \Delta \mathrm{Glu}_{30}(\mathrm{pmol} / \mathrm{mmol})$ & $114(60)$ & $195(129)$ & $122(66)$ & $85(87)$ & $<0.001$ & $<0.001$ & $<0.001$ \\
\hline Total cholesterol (mmol/l) & $4.6(0.9)$ & $4.9(0.9)$ & $5.4(1.0)$ & $5.2(1.1)$ & 0.154 & 0.015 & 0.312 \\
\hline LDL cholesterol (mmol/l)' & $2.4(0.7)$ & $3.1(0.8)$ & $3.4(1.0)$ & $3.3(1.0)$ & 0.002 & 0.098 & 0.332 \\
\hline HDL cholesterol (mmol/l) & $1.8(0.5)$ & $1.2(0.3)$ & $1.3(0.3)$ & $1.1(0.3)$ & $<0.001$ & 0.354 & 0.263 \\
\hline Systolic blood pressure (mmHg) & $117(10)$ & $128(15)$ & $135(19)$ & $132(12)$ & 0.004 & 0.008 & 0.325 \\
\hline Diastolic blood pressure (mmHg) & $75(8)$ & $81(10)$ & $83(11)$ & $83(10)$ & 0.018 & 0.166 & 0.431 \\
\hline Anti-hypertensive medication (yes) & $0(0 \%)$ & $16(28 \%)$ & $20(30 \%)$ & $7(33 \%)$ & 0.002 & 0.786 & 0.651 \\
\hline Smoking (yes) & $5(19 \%)$ & $16(28 \%)$ & $20(30 \%)$ & $7(33 \%)$ & 0.345 & 0.786 & 0.651 \\
\hline
\end{tabular}

Data are given as mean (s.D.) or number (\%). One-way ANOVA with post-hoc comparisons (least significant difference) and $\chi^{2}$ were used to evaluate differences between groups. NW, normal weight; MO, morbidly obese; NGT, normal glucose tolerance; Pre-DM, pre-diabetes; NODM, new onset diabetes mellitus, ISI, insulin sensitivity index; LDL, low-density lipoprotein; HDL, high-density lipoprotein. 

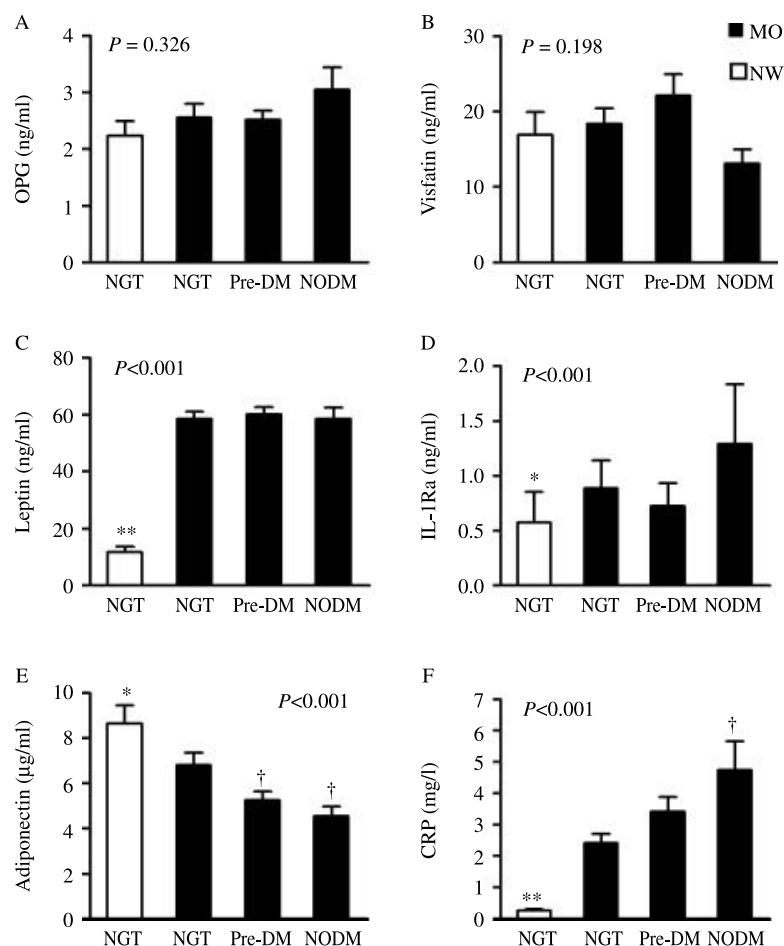

Figure 1 Baseline levels of (A) OPG; (B) visfatin; (C) leptin; (D) IL-1Ra; (E) adiponectin; and (F) CRP in normal weight (NW) subjects (white columns) with normal glucose tolerance (NGT; $n=27$ ) and in morbidly obese (MO) subjects (black columns) with NGT $(n=57)$, pre-diabetes (Pre-DM; $n=66$ ) or new onset diabetes mellitus (NODM; $n=21$ ). Data are given as mean (S.E.M).

The $P$ values indicate the group effect from the one-way ANOVA. Least significant difference procedure was used for the adjustment of multiple comparisons. ${ }^{\star} P<0.05$ and ${ }^{\star \star} P<0.001$ versus morbidly obese subjects with NGT, Pre-DM, and NODM, ${ }^{\dagger} P<0.05$ versus morbidly obese subjects with NGT.

Among the obese subjects, the leptin and IL-1Ra concentrations did not differ significantly across the glucose tolerance categories. Notably, a different pattern emerged for the serum levels of adiponectin and CRP; significantly higher serum levels of CRP and lower levels of adiponectin were observed in normoglycemic MO subjects when compared with the normoglycemic NW subjects (Fig. 1E and F). Additionally, among the MO subjects, glucose intolerance was associated with lower adiponectin levels and higher CRP levels.

In the whole study population, insulin sensitivity $\left(\mathrm{ISI}_{0,120}\right)$ was negatively correlated with serum levels of OPG $(r=-0.183, P=0.016)$, leptin $(r=-0.416$, $P<0.001)$, IL-1Ra $(r=-0.216, P=0.005)$, and CRP $(r=-0.460, P<0.001)$, while it was positively correlated with adiponectin levels $(r=0.248, P=0.001)$. Stepwise multiple regression analysis including the inflammatory mediators that had a statistically significant correlation with insulin sensitivity, revealed that only CRP $(\beta=-0.330, P<0.001)$ and leptin $(\beta=-0.229 . P=0.005)$ were significant determinants of insulin sensitivity $\left(r^{2}=0.247\right)$.
OPG levels were, in the whole study population, positively correlated with CRP $(r=0.184, P=0.016)$ and visfatin $(r=0.402, P<0.001)$ levels, while they were negatively correlated with adiponectin levels $(r=-0.275, P<0.001)$.

In the MO subjects, baseline leptin levels were significantly higher in women than in men $(P<0.001)$, while baseline OPG levels were significantly higher in post-menopausal $(n=25)$ women than in pre-menopausal women $(n=78 ; P=0.034)$. No other differences in inflammatory mediators, either between men and women or between pre- and post-menopausal women, were found (data not shown).

\section{Changes during the OGTT}

As was expected, glucose and insulin levels during the OGTT showed dissimilar patterns between groups with different glucose tolerance (Fig. 2A and B). These changes in glucose and insulin levels were accompanied by several changes in the levels of adipokines- and cytokine-related variables (Fig. 3A-D). OPG, visfatin, leptin, and adiponectin levels, but not IL-1Ra and CRP levels (data not shown), changed significantly during the OGTT (effect of time). There were no statistically significant interactions between the effects of time and group for OPG, visfatin, leptin, and adiponectin, denoting that the changes in these inflammatory mediators did not differ significantly between groups (effect of time $\times$ group).
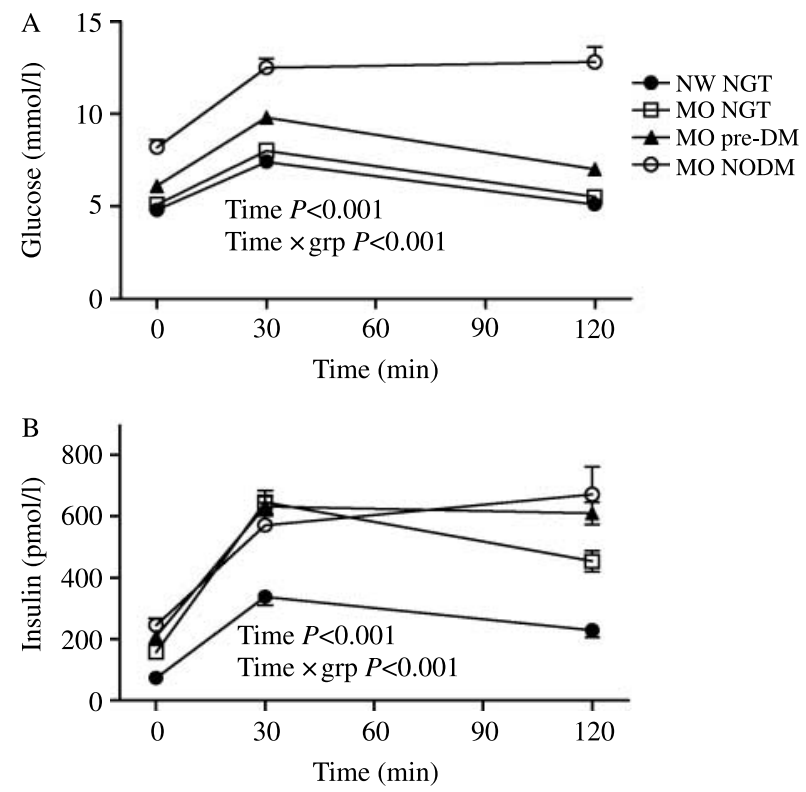

Figure 2 Changes in $(A)$ glucose and $(B)$ insulin levels during the OGTT in normal weight (NW) subjects with normal glucose tolerance (NGT; $n=27$ ) and in morbidly obese (MO) subjects with NGT $(n=57)$, pre-diabetes (Pre-DM; $n=66)$ or new onset diabetes mellitus (NODM; $n=21$ ). Data are given as mean (S.E.M).

The $P$ values indicate the time and time $\times$ group (grp) effect from the two-way repeated measure ANOVA. 

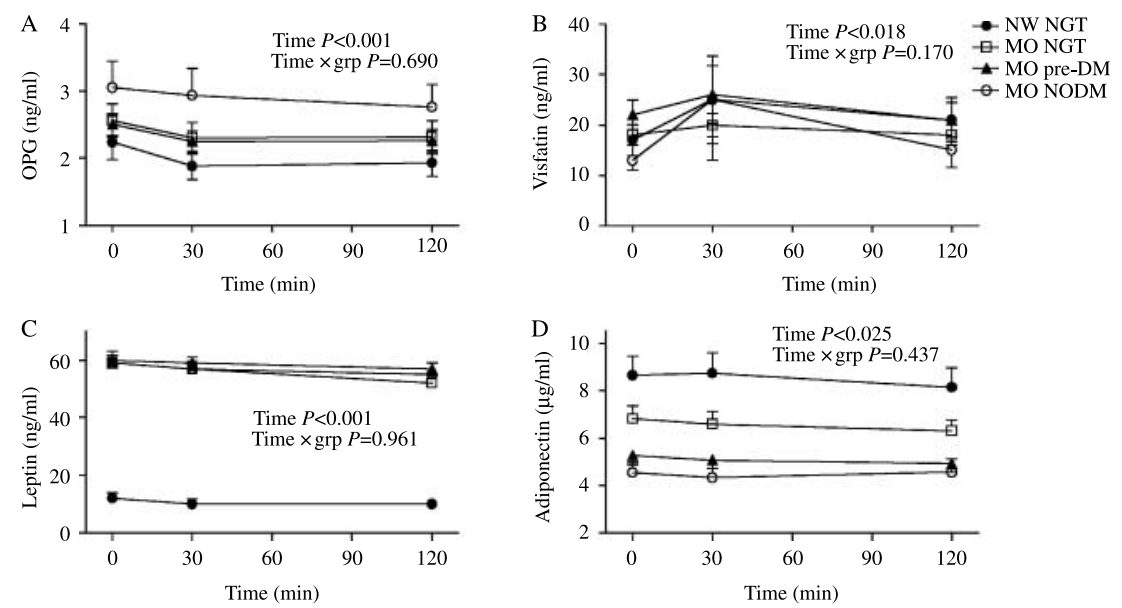

Figure 3 (A) Changes in OPG; (B) visfatin; (C) leptin; and (D) adiponectin levels during the OGTT in normal weight (NW) subjects with normal glucose tolerance (NGT; $n=27$ ) and in morbidly obese (MO) subjects with NGT $(n=57)$, pre-diabetes (pre-DM; $n=66$ ) or new onset diabetes mellitus (NODM; $n=21$ ). Data are given as mean (S.E.M). The $P$ values indicate the time and time $\times$ group (grp) effect from the two-way repeated measure ANOVA.
Owing to statistically significant main effects of time, post-hoc analyses were performed. These analyses revealed that in the whole study population, OPG levels decreased and were statistically significantly different at both 30 and $120 \mathrm{~min}$ compared to baseline (both $P<0.001$ ). Additionally, visfatin peaked at $30 \mathrm{~min}(P=0.007)$ and returned to baseline levels after $120 \mathrm{~min}(P=0.436)$. Leptin and adiponectin levels were both lower at 120 min compared to baseline levels, yet although significant, the changes were rather modest in size.

Changes in OPG $\left(\Delta \mathrm{OPG}_{0-30}\right.$ and $\left.\Delta \mathrm{OPG}_{0-120}\right)$ and visfatin $\left(\Delta\right.$ visfatin $\left._{0-30}\right)$ levels were not significantly correlated with changes in glucose or insulin levels during the first $30 \mathrm{~min}$ of the OGTT $\left(\Delta\right.$ glucose $_{0-30}$ and $\Delta$ insulin $_{0-30}$; data not shown).

\section{Discussion}

This study, which examined various inflammatory mediators in a relatively large number of MO individuals before and after an oral glucose load, has two major findings. First, both morbid obesity and glucose intolerance were associated with lower adiponectin levels and higher CRP levels. Second, OPG levels decreased and visfatin levels transiently increased after an oral glucose load, independent of obesity and glucose tolerance status.

\section{Cytokines and adipokines at baseline}

Our findings support the theory that obesity and glucose abnormalities may adversely affect CRP and adiponectin levels (3-5, 19-22). However, to our knowledge, we are the first to demonstrate within MO subjects both a stepwise increase in serum CRP levels and a concomitant decrease in serum levels of adiponectin across categories of glucose tolerance (from NGT to NODM). These findings suggest that inflammation has a role to play in the conditions characterized by insulin resistance. Indeed, in accordance with previous studies $(5,6,21,22)$, we found that CRP was negatively correlated with insulin sensitivity and adiponectin positively correlated. Furthermore, we confirm the findings from a smaller study that showed levels of IL-1Ra elevated in MO subjects and associated with insulin resistance (7). Notably, the levels of IL-1Ra did not vary across different categories of glucose tolerance in our study. CRP was, in the current study, the inflammatory marker that best predicted insulin sensitivity. Whether our observations reflect some causal relationship between inflammation, obesity, and disturbed glucose homeostasis is at present unclear. However, the interaction between inflammation and these metabolic abnormalities could clearly contribute to the increased occurrence of cardiovascular complications in obese individuals.

In the current study, we report an inverse correlation between serum levels of OPG and adiponectin. This finding is in line with an in vitro study showing that adiponectin inhibited OPG expression in osteoblasts (28). These findings may suggest an unfavorable effect of adiponectin on bone metabolism. Indeed, an inverse association between bone mineral density and adiponectin levels has been recently observed (29). In line with previous reports $(30,31)$, we found a positive correlation between serum levels of OPG and CRP, further suggesting a relationship between OPG and inflammation. While the strong and positive correlation between serum levels of OPG and visfatin has not been previously reported, neither the mechanisms nor the clinical implications of this finding are clear at present.

\section{OPG levels declined after the oral glucose load}

Our finding of a consistent decrease in OPG levels after an oral glucose challenge extends the validity of the results found in a recent study of post-menopausal Thai 
women (32) to both white MO and lean subjects of both genders. In accordance with the previous study, we demonstrated a significant decline in the OPG levels of obese and non-obese individuals during OGTT, with no significant differences in changes in OPG levels between groups. This suggests that the changes in OPG may be independent of obesity and glucose tolerance status.

During a hyperglycemic clamp study Knudsen et al. showed that decreasing levels of OPG were negatively correlated with changes in insulin levels but not with changes in glucose concentrations, indicating that hyperinsulinemia may suppress OPG synthesis and/or release (33). Two recent in vitro studies have partly supported this theory, and have shown insulinsuppressed OPG synthesis in adipocytes and vascular smooth muscle cells $(34,35)$. Another in vitro study found insulin to have no effect on OPG release in vascular endothelial cells (36). By contrast, glucose did not influence either OPG synthesis from vascular smooth muscle cells or OPG release from endothelial cells $(35,36)$. Although we have demonstrated that OPG levels decreased after an oral glucose load, we cannot confirm any correlation between the changes in insulin and OPG levels. However, this lack of correlation does not rule out the hypothesis that increased endogenous insulin secretion, observed after an oral glucose load, may inhibit OPG synthesis and/or release.

OPG counteracts the action of RANKL as well as TNF-related apoptosis inducing ligand (37). A decline in OPG levels could therefore potentially lead to enhanced activity of these TNF-related cytokines. However, the potential biological consequences of this OGTT-related decrease in OPG levels are at present unclear.

\section{Visfatin levels increased after the oral glucose load}

It has been hypothesized that visfatin may influence insulin secretion by modulating $\beta$-cell function (13). Furthermore, Haider et al. demonstrated both that visfatin released from adipocytes was enhanced by glucose in vitro and that hyperglycemia, during a glucose clamp, was associated with increased visfatin levels, which could be reversed by co-infusion of insulin (38). Haider et al. also found, in pregnant women both with and without gestational diabetes (GDM), transiently increased visfatin levels after an oral glucose load (39). Other studies, however, have failed to demonstrate any visfatin response during an OGTT $(40,41)$. Our finding of a transient increase in visfatin levels during the OGTT partly supports the findings observed in pregnant women (39). Yet, contrasting that study, which showed a reduced visfatin response in women with GDM, with our own, we have found the visfatin response to be independent of obesity and glucose tolerance status. Although we did not find any correlation between changes in visfatin and changes in glucose or insulin, the possibility that glucose and/or insulin may be involved in the regulation of visfatin cannot be ruled out.

\section{Limitations}

This study has a number of limitations. First, the study population consisted of mainly middle-aged white subjects, limiting the generalizability of our findings to other age groups and ethnicities. Secondly, the crosssectional design made it impossible to establish any cause and effect relationships. Thirdly, while we present data on the short-term effect of glucose on levels of various adipokines and cytokine related mediators, this may not necessarily reflect the situation in obese patients with long-term exposure to increased levels of glucose and insulin. Finally, although the altered levels of visfatin and OPG during OGTT seem consistent, the biological effects of these alterations are at present unclear.

\section{Conclusions}

In conclusion, both morbid obesity and glucose intolerance were associated with lower adiponectin levels and higher CRP levels. These findings give support to the theory that inflammation has a role to play in these metabolic conditions. In addition, OPG levels decreased and visfatin levels transiently increased after an OGTT, suggesting a possible regulator pathway for these proteins. Importantly, it must be noted that the mechanisms by which glucose and insulin regulate adipokines and cytokines, and vice versa, are not yet fully understood. Further mechanistic studies are therefore needed in order to address these issues.

\section{Declaration of interest}

No potential conflicts of interest relevant to this article were reported.

\section{Funding}

Dag Hofsø has received unrestricted educational grants from Novo Nordisk A/S, South-Eastern Norway Regional Health Authority and Vestfold Hospital Trust.

\section{Acknowledgements}

We would like to thank Hanne Aspaas and Berit Mossing Bjørkås for their assistance with sampling and logistics.

\section{References}

1 Zimmet P, Alberti KG \& Shaw J. Global and societal implications of the diabetes epidemic. Nature $2001 \mathbf{4 1 4} 782-787$.

2 Wellen KE \& Hotamisligil GS. Inflammation, stress, and diabetes. Journal of Clinical Investigation 2005115 1111-1119.

3 Visser M, Bouter LM, McQuillan GM, Wener MH \& Harris TB. Elevated C-reactive protein levels in overweight and obese adults. Journal of the American Medical Association 1999282 2131-2135. 
4 Ford ES. Body mass index, diabetes, and C-reactive protein among US adults. Diabetes Care 199922 1971-1977.

5 Festa A, D’Agostino R Jr, Howard G, Mykkanen L, Tracy RP \& Haffner SM. Chronic subclinical inflammation as part of the insulin resistance syndrome: the insulin resistance atherosclerosis study (IRAS). Circulation $200010242-47$.

6 Yudkin JS, Stehouwer CD, Emeis JJ \& Coppack SW. C-reactive protein in healthy subjects: associations with obesity, insulin resistance, and endothelial dysfunction: a potential role for cytokines originating from adipose tissue? Arteriosclerosis, Thrombosis, and Vascular Biology 199919 972-978.

7 Meier CA, Bobbioni E, Gabay C, Assimacopoulos-Jeannet F, Golay A \& Dayer JM. IL-1 receptor antagonist serum levels are increased in human obesity: a possible link to the resistance to leptin? Journal of Clinical Endocrinology and Metabolism 200287 1184-1188.

8 Omland T, Drazner MH, Ueland T, Abedin M, Murphy SA, Aukrust P \& De Lemos JA. Plasma osteoprotegerin levels in the general population: relation to indices of left ventricular structure and function. Hypertension $2007 \mathbf{4 9} 1392-1398$.

9 Omland T, Ueland T, Jansson AM, Persson A, Karlsson T, Smith C, Herlitz J, Aukrust P, Hartford M \& Caidahl K. Circulating osteoprotegerin levels and long-term prognosis in patients with acute coronary syndromes. Journal of the American College of Cardiology 200851 627-633.

10 Hofbauer LC \& Schoppet M. Clinical implications of the osteoprotegerin/RANKL/RANK system for bone and vascular diseases. Journal of the American Medical Association 2004292 490-495.

11 Simonet WS, Lacey DL, Dunstan CR, Kelley M, Chang MS, Luthy R, Nguyen HQ, Wooden S, Bennett L, Boone T, Shimamoto G, DeRose M, Elliott R, Colombero A, Tan HL, Trail G, Sullivan J, Davy E, Bucay N, Renshaw-Gegg L, Hughes TM, Hill D, Pattison W, Campbell P, Sander S, Van G, Tarpley J, Derby P, Lee R \& Boyle WJ. Osteoprotegerin: a novel secreted protein involved in the regulation of bone density. Cell 199789 309-319.

12 Considine RV, Sinha MK, Heiman ML, Kriauciunas A, Stephens TW, Nyce MR, Ohannesian JP, Marco CC, McKee LJ, Bauer TL \& Caro JF. Serum immunoreactive-leptin concentrations in normal-weight and obese humans. New England Journal of Medicine $1996334292-295$.

13 Revollo JR, Korner A, Mills KF, Satoh A, Wang T, Garten A, Dasgupta B, Sasaki Y, Wolberger C, Townsend RR, Milbrandt J, Kiess W \& Imai S. Nampt/PBEF/Visfatin regulates insulin secretion in beta cells as a systemic NAD biosynthetic enzyme. Cell Metabolism 2007 6 363-375.

14 Berndt J, Kloting N, Kralisch S, Kovacs P, Fasshauer M, Schon MR, Stumvoll M \& Bluher M. Plasma visfatin concentrations and fat depot-specific mRNA expression in humans. Diabetes $2005 \mathbf{5 4}$ 2911-2916.

15 Korner A, Garten A, Bluher M, Tauscher R, Kratzsch J \& Kiess W. Molecular characteristics of serum visfatin and differential detection by immunoassays. Journal of Clinical Endocrinology and Metabolism 200792 4783-4791.

16 Ingelsson E, Larson MG, Fox CS, Yin X, Wang TJ, Lipinska I, Pou KM, Hoffmann U, Benjamin EJ, Keaney JF Jr \& Vasan RS. Clinical correlates of circulating visfatin levels in a communitybased sample. Diabetes Care 200730 1278-1280.

17 Chen MP, Chung FM, Chang DM, Tsai JC, Huang HF, Shin SJ \& Lee YJ. Elevated plasma level of visfatin/pre-B cell colonyenhancing factor in patients with type 2 diabetes mellitus. Journal of Clinical Endocrinology and Metabolism 2006 91 295-299.

18 Moschen AR, Kaser A, Enrich B, Mosheimer B, Theurl M, Niederegger $\mathrm{H} \&$ Tilg $\mathrm{H}$. Visfatin, an adipocytokine with proinflammatory and immunomodulating properties. Journal of Immunology $2007 \mathbf{1 7 8} 1748-1758$.

19 Arita Y, Kihara S, Ouchi N, Takahashi M, Maeda K, Miyagawa J, Hotta K, Shimomura I, Nakamura T, Miyaoka K, Kuriyama H, Nishida M, Yamashita S, Okubo K, Matsubara K, Muraguchi M, Ohmoto Y, Funahashi T \& Matsuzawa Y. Paradoxical decrease of an adipose-specific protein, adiponectin, in obesity. Biochemical and Biophysical Research Communications 1999257 79-83.
20 Hotta K, Funahashi T, Arita Y, Takahashi M, Matsuda M, Okamoto Y, Iwahashi H, Kuriyama H, Ouchi N, Maeda K, Nishida M, Kihara S, Sakai N, Nakajima T, Hasegawa K, Muraguchi M, Ohmoto Y, Nakamura T, Yamashita S, Hanafusa T \& Matsuzawa Y. Plasma concentrations of a novel, adipose-specific protein, adiponectin, in type 2 diabetic patients. Arteriosclerosis, Thrombosis, and Vascular Biology 200020 1595-1599.

21 Weyer C, Funahashi T, Tanaka S, Hotta K, Matsuzawa Y, Pratley RE \& Tataranni PA. Hypoadiponectinemia in obesity and type 2 diabetes: close association with insulin resistance and hyperinsulinemia. Journal of Clinical Endocrinology and Metabolism 200186 1930-1935.

22 Tschritter O, Fritsche A, Thamer C, Haap M, Shirkavand F, Rahe S, Staiger H, Maerker E, Haring H \& Stumvoll M. Plasma adiponectin concentrations predict insulin sensitivity of both glucose and lipid metabolism. Diabetes 200352 239-243.

23 American Diabetes Association. Diagnosis and classification of diabetes mellitus. Diabetes Care 200831 55S-60S.

24 Gutt M, Davis CL, Spitzer SB, Llabre MM, Kumar M, Czarnecki EM, Schneiderman N, Skyler JS \& Marks JB. Validation of the insulin sensitivity index $\left(\mathrm{ISI}_{0,120}\right)$ : comparison with other measures. Diabetes Research and Clinical Practice 200047 177-184.

25 Haffner SM, Miettinen H, Gaskill SP \& Stern MP. Decreased insulin secretion and increased insulin resistance are independently related to the 7-year risk of NIDDM in Mexican-Americans. Diabetes 199544 1386-1391.

26 Phillips DIW, Clark PM, Hales CN \& Osmond C. Understanding oral glucose tolerance: comparison of glucose or insulin measurements during the oral glucose tolerance test with specific measurements of insulin resistance and insulin secretion. Diabetic Medicine 199411 286-292.

27 Wu TL, Tsao KC, Chang CP, Li CN, Sun CF \& Wu JT. Development of ELISA on microplate for serum C-reactive protein and establishment of age-dependent normal reference range. Clinica Chimica Acta 2002322 163-168.

28 Luo XH, Guo LJ, Xie H, Yuan LQ, Wu XP, Zhou HD \& Liao EY. Adiponectin stimulates RANKL and inhibits OPG expression in human osteoblasts through the MAPK signaling pathway. Journal of Bone and Mineral Research 200621 1648-1656.

29 Jurimae J, Rembel K, Jurimae T \& Rehand M. Adiponectin is associated with bone mineral density in perimenopausal women. Hormone and Metabolic Research 200537 297-302.

30 Gannage-Yared MH, Yaghi C, Habre B, Khalife S, Noun R, Germanos-Haddad M \& Trak-Smayra V. Osteoprotegerin in relation to body weight, lipid parameters insulin sensitivity, adipocytokines, and C-reactive protein in obese and non-obese young individuals: results from both cross-sectional and interventional study. European Journal of Endocrinology 2008158 353-359.

31 Xiang GD, Xu L, Zhao LS, Yue L \& Hou J. The relationship between plasma osteoprotegerin and endothelium-dependent arterial dilation in type 2 diabetes. Diabetes 200655 2126-2131.

32 Chailurkit LO, Chanprasertyothin S, Rajatanavin R \& Ongphiphadhanakul B. Reduced attenuation of bone resorption after oral glucose in type 2 diabetes. Clinical Endocrinology 2008 68 858-862.

33 Knudsen ST, Jeppesen P, Poulsen PL, Andersen NH, Bek T, Schmitz O, Mogensen CE \& Rasmussen LM. Plasma concentrations of osteoprotegerin during normo- and hyperglycaemic clamping. Scandinavian Journal of Clinical and Laboratory Investigation 2007 67 135-142.

34 An JJ, Han DH, Kim DM, Kim SH, Rhee Y, Lee EJ \& Lim SK. Expression and regulation of osteoprotegerin in adipose tissue. Yonsei Medical Journal $2007 \mathbf{4 8} 765-772$.

35 Olesen P, Ledet T \& Rasmussen LM. Arterial osteoprotegerin: increased amounts in diabetes and modifiable synthesis from vascular smooth muscle cells by insulin and TNF- $\alpha$. Diabetologia 200548 561-568.

36 Secchiero P, Corallini F, Pandolfi A, Consoli A, Candido R, Fabris B, Celeghini C, Capitani S \& Zauli G. An increased osteoprotegerin 
serum release characterizes the early onset of diabetes mellitus and may contribute to endothelial cell dysfunction. American Journal of Pathology $20061692236-2244$.

37 Vitovski S, Phillips JS, Sayers J \& Croucher PI. Investigating the interaction between osteoprotegerin and receptor activator of NF- $\kappa \mathrm{B}$ or tumor necrosis factor-related apoptosis-inducing ligand: evidence for a pivotal role for osteoprotegerin in regulating two distinct pathways. Journal of Biological Chemistry $200728231601-31609$.

38 Haider DG, Schaller G, Kapiotis S, Maier C, Luger A \& Wolzt M. The release of the adipocytokine visfatin is regulated by glucose and insulin. Diabetologia 200649 1909-1914.

39 Haider DG, Handisurya A, Storka A, Vojtassakova E, Luger A, Pacini G, Tura A, Wolzt M \& Kautzky-Willer A. Visfatin response to glucose is reduced in women with gestational diabetes mellitus. Diabetes Care 200730 1889-1891.
40 Marcinkowska M, Lewandowski KC, Lewinski A, Bienkiewicz M, Basinska-Lewandowska M, Salata I \& Randeva HS. Visfatin levels do not change after the oral glucose tolerance test and after a dexamethasone-induced increase in insulin resistance in humans. Endokrynologia Polska 200758 188-194.

41 Li L, Yang G, Li Q, Tang Y, Yang M, Yang H \& Li K. Changes and relations of circulating visfatin, apelin, and resistin levels in normal, impaired glucose tolerance, and type 2 diabetic subjects. Experimental and Clinical Endocrinology and Diabetes $2006 \mathbf{1 1 4}$ 544-548.

Received 19 May 2009

Accepted 7 June 2009 